

\title{
Estado e concentração de capital no nacional-desenvolvimentismo
}

\author{
State and concentration of capital in the \\ national developmentalism
}

Marcus Iononi*

\section{Resumo}

Estas notas de pesquisa dedicam-se ao tema da relação do Estado com a concentração de capital e perseguem dois caminhos para abordá-lo. Por um lado, há um breve resgate teórico do tema da concentração de capital na economia política de enraizamento clássico, situada no marxismo e no pensamento desenvolvimentista crítico da ortodoxia neoclássica. Por outro lado, há também uma breve descrição e análise da concentração de capital no período nacional-desenvolvimentista brasileiro, que se abriu desde a Revolução de 1930 e entrou em crise derradeira na década de 1980. Mas esta breve exposição abrange apenas o espaço temporal entre 1930 e 1964.

Palavras-chave: Estado, concentração de capital, nacional-desenvolvimentismo, economia política.

\begin{abstract}
These research notes focus on the relationship between the state and the concentration of capital and pursue two approaches. On the one hand, there is a brief theoretical rescue of the theme of the concentration of capital in the political economy of classic rooting, situated in Marxism and in the critical developmentalist thinking of neoclassical orthodoxy. On the other hand, there is also a brief description and analysis of the concentration of capital in the Brazilian national developmental period, which has been open since the 1930 Revolution and entered into a final crisis in the 1980s. But this brief exposition only covers the temporal space between 1930 and 1964.
\end{abstract}

Keywords: State, concentration of capital, national developmentalism, political economy. 


\section{INTRODUÇÃO}

Estas notas de pesquisa dedicam-se ao tema da relação do Estado com a concentração de capital e perseguem dois caminhos para abordá-lo. Por um lado, há um breve resgate teórico do tema da concentração de capital na economia política de enraizamento clássico, situada no marxismo e no pensamento desenvolvimentista crítico da ortodoxia neoclássica. Por outro lado, há também uma breve descrição e análise da concentração de capital no período nacional-desenvolvimentista brasileiro, que se abriu desde a Revolução de 1930 e entrou em crise derradeira na década de 1980. Mas esta breve exposição abrange apenas o espaço temporal entre 1930 e 1964.

Visa-se abordar a concentração de capital em geral, mas principalmente sua ocorrência no Brasil, como um processo que extrapola a dinâmica exclusiva do mercado, tendo relação embora a concentração seja uma tendência do processo de acumulação do capital ocorrente em outros setores da atividade econômica. Buscase abordar a participação do Estado em um processo avançado da acumulação de capital, a centralização de capital, que se segue à concentração. A abordagem apóia na revisão da literatura e, no caso do Brasil, no método de pesquisa do process tracing: levantam-se informações e dados empíricos e, simultaneamente, busca-se interpretálos associando-os a argumentos provenientes da sociologia, da ciência política, da economia política e da economia brasileira.

Durante os governos Lula e no primeiro mandato da presidenta Dilma Rousseff, houve um papel mais ativo do Estado visando alavancar o desenvolvimento, que implicou no atendimento de demandas das corporações empresariais, direcionadas a interesses e oportunidades de negócios no mercado interno ou no mercado externo (exportações, internacionalização) ou a ambos. Nesse contexto, o crescimento, por exemplo, do volume de dinheiro movimentado em políticas de crédito subsidiado e de participação acionária, ambas por parte do BNDES, suscitou muita polêmica. Uma visão menos ideologicamente apaixonada dessas relações, ou seja, independentemente de apoiá-las ou favorecê-las, pode ser útil para a sua elucidação teórica, histórica e político-estrutural, embora a análise empírica restrinja-se a um período passado, distante dos anos 2000. A seguir segue uma seção teórica sobre o tema objeto dessas notas de pesquisa, depois a seção empírica sobre o Brasil e, por fim, as considerações gerais.

\section{ASPECTOS TEÓRICOS DAS RELAÇŌES ENTRE O ESTADO E A CONCENTRAÇÃO DO CAPITAL}

Em O Capital, Marx definiu os conceitos de concentração e centralização do capital. Na concentração de capital, grandes quantidades de meios de produção de um sistema econômico pré-capitalista, até então existentes de modo socialmente disperso, são apropriadas pelos capitalistas individuais. "Todo capital individual 
é uma concentração maior ou menor dos meios de produção, como o comando correspondente sobre um exército maior ou menor de trabalhadores" (Marx, 1867b [1998], p. 728). A concentração é o processo pelo qual ocorre o incremento do capital social, o crescimento de muitos capitalistas individuais. Por outro lado, a centralização de capital diz respeito à expropriação dos capitalistas individuais por outros capitalistas, "a transformação de muitos capitais pequenos em poucos capitais grandes".2

A concorrência é um determinante importante da centralização. Por meio dela, os grandes capitais excluem dos mercados os pequenos, ocorrendo a "expropriação de muitos capitalistas por poucos".3 Além disso, o desenvolvimento capitalista "aumenta a dimensão mínima do capital individual exigido para se levar adiante um negócio em condições normais". ${ }^{4} \mathrm{O}$ momento histórico de largada na produção capitalista é importante. Na centralização, o capital social já existente tem sua distribuição modificada. "Num dado ramo de atividades, a centralização terá alcançado seu limite extremo quando todos os capitais nele investidos se fundirem num único capital".5 Marx esclarece que a redução dos preços das mercadorias é a principal arma da concorrência. "Não se alterando as demais circunstâncias, o barateamento das mercadorias depende da produtividade do trabalho, e este, da escala da produção".

A centralização é uma tendência observada em todos os ramos da indústria e é maior naquelas atividades em que a composição orgânica do capital é maior. "There are several industrial branches in which this concentration is particularly striking: coal mining had hundreds of companies during the 19th century in a country like France (there were almost 200 in Belgium); the automobile industry had 100 or more firms at the beginning of the century in countries like the United States and England, whereas today their number has been reduced to four, five or six such companies at most" (Mandel, 1967[2002], p. 36). Com a centralização, o capital industrial amplia a escala de suas operações. Marx menciona as aquisições (anexações) e fusões, facilitadas pela sociedade anônima e pela bolsa de valores. A concentração é um processo lento em comparação com a centralização. “O mundo ainda estaria sem estradas de ferro, se tivesse de esperar que a acumulação capacitasse alguns capitais isolados para a construção de uma ferrovia. A centralização, entretanto, por meio da organização de sociedades anônimas, cria num instante as condições para uma tarefa dessa ordem" (Marx, idem, p. 731).

Os economistas marxistas Baran e Sweezy (1966) avaliam que, apesar de identificar a centralização de capitais, o modelo de Marx foi construído com base no mercado competitivo, não tendo ele investigado e explorado as consequências de um sistema econômico estruturado em corporações monopolistas, ou seja, em mercados não competitivos. Acreditam também que nem Hilferding, marxista que escreveu a primeira obra sobre o capital monopolista, e nem Lenin, que por ele se influenciou ao escrever sobre o imperialismo, exploraram as consequências da predominância do capital monopolista na economia capitalista. ${ }^{7}$ 
Baran e Sweezy consideram-se pioneiros nessa tarefa. Delimitaram como objeto de análise a economia dos EUA, potência capitalista e país onde viviam. Para eles, na fase monopolista, o capitalismo só pode ser compreendido se o monopólio estiver no centro da análise. Nesse sentido, o tema dessa influente obra marxista, publicada em parceria, é a geração e absorção do excedente no capitalismo monopolista, condição que estrutura os vínculos dos agentes econômicos com a superestrutura política, cultural e ideológica. Baran e Sweezy enfatizam o papel crucial da mudança tecnológica no desenvolvimento do capitalismo monopolista, inclusive seu impacto nos trabalhadores, mas não aprofundam esse último aspecto. ${ }^{8}$

O ponto de partida é que a unidade econômica típica não é mais a pequena firma, mas a empresa em grande escala, que responde por um montante significativo da produção de uma indústria ou de várias delas, controla seus preços, volume de produção e as modalidades e montantes de seus investimentos. ${ }^{9}$ A corporação gigante é controlada por um grupo que se autoperpetua, composto pelo conselho de administração e pelos diretores executivos. Em geral, cada corporação tem independência financeira, obtida pela geração interna de fundos (corporate bonds) que ficam à sua disposição. Avaliam que a concentração de poder no interior das corporações torna ultrapassada a ideia de que o grupo de interesse é a unidade estrutural fundamental da sociedade capitalista, conforme pensam os pluralistas. Os grupos de interesse continuam a existir, mas sua importância diminuiu significativamente, sendo dispensáveis para a formulação de um modelo apropriado da economia dos EUA.

Embora Baran e Sweezy não ignorassem o Estado, sua obra sobre o capital monopolista priorizou a reflexão econômica. Eles não fizeram teorizaram as relações das grandes corporações com o Estado. Quem avançou mais nessa direção foi, entre outros, o economista Mandel (1972), na obra intitulada Capitalismo Tardio. O nome do livro diz respeito a uma das três fases do capitalismo, segundo o autor, quais sejam: o capitalismo competitivo, o imperialismo clássico e o capitalismo tardio. Cada fase vincula-se a uma revolução tecnológica, respectivamente, à primeira, segunda e terceira revolução tecnológica. Essa obra de Mandel analisou o último período, distinguido no título do livro.

Ele delimita a primeira fase do capitalismo entre o final do século XVIII e a década de 1890, ou seja, da Revolução Industrial à onda longa da primeira revolução tecnológica, iniciada na crise de 1847. Nesse último período, a máquina a vapor de fabricação mecânica - a maquinofatura - torna-se a principal máquina motriz, substituindo a máquina a vapor de fabricação artesanal ou manufatureira, até então predominante, que inicialmente revolucionou a indústria. Essa primeira grande fase se subdivide, então, em dois longos períodos - ondas longas - de cerca de 50 anos. A segunda fase é a imperialista, cuja primeira onda vai até a II Guerra Mundial. Caracteriza-se "pela aplicação generalizada dos motores elétricos e a combustão a todos os ramos da indústria" e está inserida na segunda revolução tecnológica. A terceira fase, o capitalismo tardio, que inaugura outra onda longa, é também imperialista e articula- 
se à terceira revolução tecnológica, liderada "pelo controle generalizado das máquinas por meio de aparelhagem eletrônica (bem como pela gradual introdução da energia nuclear)".10

A expansão internacional do capitalismo, fundamental para alavancar e conduzir o processo de centralização do capital para fora dos limites exclusivos das economias nacionais, não foi obra apenas do mercado, mas também do Estado. "The State [...] had to use political and often military force to remove the obstacles which pre-capitalist classes and states represented to the unrestricted expansion of the capitalist export of commodities"111Mas a exportação será ainda mais abrangente, alcançando os próprios meios de produção, o capital. Por fim, além da internacionalização das mercadorias e da produção, a centralização do capital em escala mundial desdobra-se também na internacionalização da propriedade, quando capitais provenientes de diferentes nações controlam as sociedades anônimas.

"The early capitalist era of free competition had been characterized by a relative international immobility of capital. Concentration of capital remained predominantly national; centralization exclusively so". Porém, com o avanço da centralização do capital em nível internacional, no período que se segue à Segunda Guerra Mundial, a ampliação das funções do Estado, que já se verificara no estágio imperialista do início do século $X X$, dá um salto, sendo esse novo ativismo estatal uma das características marcantes de uma nova fase, o capitalismo tardio, na qual, desde o início, "the coercive power of the bourgeois State intervened ever more directly in the economy, both to ensure the smooth collection of monopoly surplus-profits abroad and to guarantee conditions for smooth capital accumulation at home".12

Entre as novas funções exercidas pelo Estado, Mandel destaca o aumento substantivo das despesas com armamentos, para respaldar militarmente a propensão imperialista à expansão da exportação não meramente de mercadorias, mas também de capitais, marca emblemática do capitalismo tardio. O militarismo implica um crescimento do aparato estatal. Ademais, o aumento da influência política da classe operária e a crescente luta de classes geram concessões, como a ampliação da legislação social, visando tanto responder às mobilizações sociais e a abrandar os conflitos de classe quanto garantir os interesses gerais da reprodução ampliada de capital, que depende, entre outros fatores, da força de trabalho.

Mas outras funções do Estado também se desenvolvem no capitalismo tardio. $\mathrm{O}$ Leviatã aprofunda o planejamento econômico; socializa custos e perdas em várias áreas importantes da produção, que, cada vez mais, tendem a mobilizar volumosos montantes de capital, devido à incorporação da inovação tecnológica de ponta; financia pesquisas em ciência e tecnologia para promover o desenvolvimento; financia e subsidia grandes investimentos empresariais; contorna dificuldades de valorização do capital e administra crises, função esta que Offe (1984) também enfatiza. Para Mandel, os Estados dos países centrais - nos quais o capitalismo tardio se configura pioneiramente - são imperialistas, cumprem o "papel de instrumento da competição 
interimperialista".13 A ampliação das funções do Estado corresponde ao aumento de sua autonomia. "The growing hypertrophy and growing autonomy of the late capitalist State are historically a corollary of the increasing difficulties of a smooth valorization of capital and realization of surplus-value". ${ }^{14}$

Vários autores neomarxistas enfatizam essa maior presença do Estado no capitalismo tardio, como Nicos Poulantzas, Ralph Miliband e Joachim Hirsch. Eles abordam o Estado no contexto de suas relações estruturais com o capital monopolista, quando se intensifica o que chamam de politização da economia. Devido à ausência de certas condições para a reprodução espontânea, o Estado passa a desempenhar papeis econômicos e ideológicos estratégicos para a acumulação de capital, tornandose muito mais importante do que havia sido quando fora, sobretudo, um aparelho repressivo e guardião da propriedade privada dos meios de produção.

Nesse pano de fundo geral, são formuladas diferentes explicações sobre o novo papel do Estado capitalista perante um sistema econômico internacional cada vez mais protagonizado pelos interesses e ações das grandes corporações nos quatro cantos do mundo. Algumas delas, de um modo ou de outro, identificam e exploram a ideia de dependência estrutural do Estado em relação ao capital (Przeworski, 1990 [1995]), que remonta à obra A Ideologia Alemã, Marx e Engels, escrita em 1846. ${ }^{15}$

\footnotetext{
It is therefore obvious that as soon as the bourgeoisie has accumulated money, the state has to beg from the bourgeoisie and in the end it is actually bought up by the latter. This takes place in a period in which the bourgeoisie is still confronted by another class, and consequently the state can retain some appearance of independence in relation to both of them. Even after the state has been bought up, it still needs money and, therefore, continues to be dependent on the bourgeoisie; nevertheless, when the interests of the bourgeoisie demand it, the state can have at its disposal more funds than states which are less developed and, therefore, less burdened with debts. However, even the least developed states of Europe, those of the Holy Alliance, are inexorably approaching this fate, for they will be bought up by the bourgeoisie (Marx, 1846). ${ }^{16}$
}

No capitalismo, opera a tendência à dependência estrutural do Estado em relação ao capital, ou seja, o poder público depende das relações capitalistas de produção. Os governantes e a burocracia pública dependem do capital para arrecadarem recursos orçamentários, com os quais o Estado paga seus funcionários e executa as políticas públicas. A acumulação é uma função do lucro. Sem lucro não há salário. Sem lucro e salário não há impostos pagos pelos agentes econômicos para financiar o Estado como organização política. A acumulação de capital é um constrangimento estrutural para o Estado. Mas isso não significa adotar uma visão funcionalista das relações entre Estado e economia no capitalismo, como se ambos compusessem um equilíbrio dinâmico. Há contradições, e não apenas tendências de manutenção do sistema.

Nos anos 1970, os neomarxistas avaliaram que o poder público do capital havia aumentado em decorrência das mudanças econômicas estruturais em curso no século XX, sobretudo após a Grande Depressão. Entre elas, destacava-se precisamente 
a consolidação do capital monopolista, que subvertia as condições da competição econômica e impactava também no conteúdo das crises, cujos efeitos podiam alcançar dimensões internacionais, e não meramente nacionais ou regionais.

Nesse contexto de centralização do capital em escala nacional e internacional, envolvendo regiões capitalistas e pré-capitalistas, centro, periferia e semiperiferia, metrópoles, colônias e semicolônias (que pode ser iluminado pelo conceito de desenvolvimento desigual e combinado, usado originalmente por Trotsky), a reprodução ampliada, que propicia a acumulação continuada do capital, passa a depender de instituições formalmente externas ao mercado, fornecidas pelo Estado. A estrutura de poder político passa a desempenhar papéis econômicos cada vez mais complexos, visando proporcionar condições de acumulação de capital em um ambiente internacional marcado pelas corporações monopolistas, cujas estratégias de mercado e desempenho impactam nas economias nacionais e nas ações governamentais. E, sobretudo a partir da crise de 1929, o Estado passa também a atuar no sentido de evitar a emergência de crises ou de amenizar seus impactos. ${ }^{17} \mathrm{O}$ surgimento das ideias keynesianas, sobretudo seu desdobramento em políticas econômicas anticíclicas, ajudou a mobilizar e legitimar alguns desses novos papeis do Estado. As mudanças na economia capitalista após a Grande Depressão e a Segunda Guerra Mundial são analisadas recorrendo-se a conceitos como "sociedade afluente", "novo estado industrial", "capital monopolista" e "capitalismo tardio".

Entre os fatores econômicos que modificam as relações entre o Estado e o capital após 1945 destacam-se: o crescimento dos oligopólios, a taxa decrescente de lucros, a escala crescente dos investimentos, as recorrentes crises de demanda e as políticas sociais, às quais Offe (1984) aborda mediante o conceito de desmercantilização. Por outro lado, o Estado e o capital têm que lidar com crescentes problemas de legitimação e com a militância dos trabalhadores.

Além do neomarxismo, autores que pesquisam sobre o desenvolvimento também se preocuparam com as relações do Estado com a acumulação do capital. Eles investigaram o papel do Estado na industrialização retardatária, como na Alemanha, Japão, Coreia e Taiwan, tanto nos seus estágios iniciais, centrados na produção destinada ao consumo individual, quanto nos mais avançados, quando as indústrias também produzem para o consumo produtivo, fabricando, em larga escala, bens intermediários, infraestrutura e bens de capital.

Peter Evans (1995 [2004]) analisa a industrialização tardia apoiado no neoinstitucionalismo histórico. Influenciado pelos estudos de Charles Tilly sobre a sociologia histórica da formação do Estado moderno e pela abordagem realista das relações internacionais, ele destaca dois papeis clássicos do Estado: guerrear e manter a ordem interna. Mas acrescenta um terceiro, cada vez mais presente, a transformação econômica. Este papel auxilia muito na realização dos outros dois. Além disso, uma bem sucedida ação econômica do Estado tende a propiciar ganhos de legitimidade, 
uma vez que esta depende do desempenho dos governantes, além, também, de aspectos procedimentais e simbólicos.

Por caminhos diferentes, a perspectiva institucional comparativa, que é uma das frentes de pesquisa do neoinstitucionalismo histórico, reforça ideias neomarxistas sobre o capitalismo tardio, em especial sobre o crescente papel econômico do Estado e sobre a relação entre legitimidade política e acumulação de capital. Mas essa abordagem argumenta que a mera vontade de intervenção econômica do Estado não é suficiente. O Estado precisa contar com instituições e capacidades que efetivamente façam a diferença, impactando nos resultados de suas ações.

A intervenção do Estado na mudança econômica leva-o a considerar as relações internacionais não só na perspectiva da defesa e da segurança nacional, mas também em termos de posicionamento e inserção do país na divisão internacional do trabalho (op. cit., pp. 30-31). Em condições de capitalismo tardio, o estímulo estatal ao crescimento industrial e à concentração de capital em alguns setores da indústria é fundamental para a competição empresarial exitosa no mercado internacional. Como dito acima, a centralização de capital resultante da concorrência é um fenômeno internacional, e não meramente do mercado nacional. Assim como no imperialismo clássico a exportação de capitais dos países desenvolvidos para as colônias, as semicolônias e para a periferia em geral foi obra conjunta do Estado e das corporações, a centralização de capital, em suas várias fases, nos países retardatários e também nos que hoje estão em desenvolvimento, ocorreu e ainda tem ocorrido com base na articulação entre o poder público e o setor privado, inclusive o de origem estrangeira.

Todo Estado nacional que, operando politicamente em uma sociedade em situação de industrialização retardatária, tenha se dedicado a promover a modernização industrial foi obrigado a levar em conta as pressões das grandes corporações internacionais para adentrar em seu correspondente mercado interno, seja para instalar as primeiras plantas, investir na expansão de novas, fazer fusões e aquisições etc. Esse problema diz respeito ao desenvolvimento desigual e combinado. Tais pressões ocorreram tanto na antiga internacionalização, que Mandel denomina imperialismo clássico, como no capitalismo tardio, que se insere em uma nova internacionalização. Ao longo do tempo, a tomada de decisão política dos Estados dos países que partiram atrasados na corrida da modernização teve que escolher, estrategicamente, um curso de ação entre algumas opções estruturalmente delimitadas que se apresentaram: contra-arrestar as pressões imperialistas para incentivar o desenvolvimento das grandes corporações locais, inclusive criando as suas próprias multinacionais; associar as multinacionais aos capitais locais no desenvolvimento de projetos industriais ou priorizar uma rota centrada na atração pura e simples de capital forâneo. Em linhas gerais, essas escolhas apresentaram-se aos países ou se combinaram em diferentes intensidades que, no processo histórico, resultaram em desenvolvimento nacional, desenvolvimento dependente ou dependência sem desenvolvimento. Nos casos de industrialização retardatária (Alemanha e Japão), do final do século XIX até a I Guerra 
Mundial, assim como em países do Leste de Ásia (Coreia do Sul e Taiwan), a partir dos anos 1950, houve níveis mais ou menos intensos, variáveis ao longo do tempo, de estratégias nacionalistas e de parcerias.

Um caso clássico de industrialização retardatária é o Japão, cuja abordagem institucional comparada, como a feita por Chalmers Johnson (1982), contribuiu para a definição do conceito de Estado desenvolvimentista e para o esclarecimento de seus mecanismos de ação. Entre eles, a referido autor destaca o papel de algumas agências piloto na modernização industrial e na concentração de capital daquele país, especialmente o desempenhado pelo MITI (Ministry of International Trade and Industry).

"As a particular pattern of late development, the Japanese case differs from the Western market economies, the communist dictatorships of development, or the new states of the postwar world. The most significant difference is that in Japan the state's role in the economy is shared with the private sector, and both the public and private sectors have perfected means to make the market work for developmental goals. This pattern has proved to be the most successful strategy of intentional development among the historical cases. It is being repeated today in newly industrializing states of East Asia - Taiwan and South Korea - and in Singapore and other South and Southeast Asian countries". ${ }^{18}$

Essa perspectiva institucional comparada, que identifica um padrão estreito de relações entre Estado e empresariado, levou Evans (1995 [2004]) a formular o conceito de autonomia inserida (embedded autonomy). A bem-sucedida ação estatal desenvolvimentista requer não apenas autonomia do Estado, no sentido dele gozar de capacidade política e técnica de formulação e execução de políticas públicas, mas também interseção de objetivos dirigidos ao meio empresarial, para que, dessa parceria, surjam projetos negociados entre as duas partes. A autonomia inserida resulta é uma idéia resultante da observação empírica, que se desdobrou em uma orientação normativa para as políticas de desenvolvimento industrial.

Como visto, há duas grandes fases de concentração do capital, a pertinente ao mercado interno e a que vai da exportação de mercadorias à exportação de capitais, ou seja, a etapa de internacionalização das corporações empresariais. Se o período histórico do mercantilismo for incluído na análise, o Estado participou de ambas as fases, de modo que a economia política da acumulação de capital transcende a operação exclusiva do livre mercado. A próxima seção aborda algo sobre a industrialização do Brasil no período nacional-desenvolvimentista, quando, com a preciosa mão visível do Estado, o capital se concentra internamente e o mercado interno se abre ao investimento externo direto. 


\section{A CONCENTRAÇÃO DE CAPITAL NO NACIONAL- DESENVOLVIMENTISMO}

No Brasil, país periférico e de industrialização retardatária, a atuação do Estado foi fundamental para a industrialização, entre outros motivos devido à escassez de capital, problema estrutural da história nacional em grande parte do século $X X$, pela inexistência de um efetivo mercado de capitais. ${ }^{19}$ Por outro lado, o objetivo governamental, gradualmente e persistentemente executado, de diversificar pela industrialização a estrutura econômica exclusivamente agrícola do país, pode ser assim explicado: "o Brasil não poderia alcançar elevado ritmo de crescimento se continuasse a se apoiar basicamente na exportação de seus principais produtos primários, cujo mercado mundial estava em retração".20

O Estado já havia apoiado a concentração de capital ocorrida na economia de mercado pré-industrial, estruturada no modelo agrário-exportador. O principal exemplo foi o próprio conjunto do empreendimento cafeeiro - a vanguarda do sistema econômico desde o Segundo Reinado até a Primeira República -, que envolvia financiamento, investimento, produção, transporte, armazenamento e comércio exportador. As políticas governamentais de imigração, de valorização do café e de defesa da renda do setor cafeeiro exemplificam a participação do Estado na concentração de capital no então principal centro de produção internacional dessa lavoura (Furtado, 1959; Cardoso, 1993). A própria defesa do café propiciou que houvesse diversificação dos investimentos, que, em alguma medida, puderam também ser destinados à indústria. Posteriormente, a ação do Estado brasileiro alavancou também a concentração de capital industrial nas duas fases da substituição de importações, a dos bens de consumo duráveis e a dos bens de produção (Mello, 1982).

Em resposta à Grande Depressão, que gerou uma forte escassez de divisas, mas também por razões políticas internas, o Estado brasileiro passou a implementar políticas que promoveram a industrialização e alavancaram a concentração de capital $^{21}$, inicialmente na indústria de bens de consumo não-duráveis, como a têxtil e a de alimentos, e de alguns bens de capital, que, já nos anos 1930, beneficiaram-se de um estímulo maior, em resposta à crise internacional. ${ }^{22}$ Naquela década, fatores como a redução das exportações, as limitações às importações, devido à restrição cambial, e a manutenção da demanda interna por produtos manufaturados, em função da política de sustentação da renda cafeeira (compra do excedente de produção, seguida pela queima de grande parte do estoque e pela estatização [moratória] das dívidas dos cafeicultores) explicam o impulso à industrialização no Brasil de então. Indústrias anteriores à Revolução de 1930 - como de algodão, vestuário, calçados, produtos alimentícios e bebidas (Suzigan, 1984) - puderam ganhar novo alento com a entrada diferente e inédita, ocorrida ao longo do tempo, do Estado no processo de modernização industrial. Mas também surgiram novas firmas industriais e indústrias. 
Após a Depressão, as políticas econômicas configuraram o modelo de desenvolvimento ancorado na substituição de importações, que teve na política cambial um dos seus principais dispositivos (Baer, op. cit., Van der Laan et alli, 2012). Diferentemente do modelo agroexportador, que tinha seu centro dinâmico na demanda externa, a partir da década de 1930, a produção industrial substitutiva de importações e a produção agrícola encontram no mercado interno a força motriz do desenvolvimento.

A ação industrializante do Estado aprofundou-se durante e após a Segunda Guerra Mundial, principalmente a partir dos anos 1950 (Baer, 1966). Do ponto de vista das finanças do Estado, os incentivos à industrialização foram, em um primeiro momento (fim dos anos 1940 e início dos anos 1950), uma decorrência indireta das políticas de controle cambial executadas para corrigir desequilíbrios na balança de pagamentos. Nas décadas de 1950 e 1960, tais instrumentos passaram a ser usados de modo voluntário, pelos decisores do Estado, para servirem à política de industrialização do país (idem, p. 193; Suzigan, 1984, p. 133).

Durante a Segunda Guerra, o setor manufatureiro, como foi o caso da indústria têxtil, beneficiou-se tanto de um relativo aumento das exportações, sobretudo para a Europa Ocidental, como da diminuição da concorrência dos produtos. A agricultura ainda predominava na economia brasileira, mas a participação da indústria no produto nacional crescia mais rapidamente que a do setor primário (Baer, op. cit.; Suzigan, 1984). Em 1942, durante o conflito bélico internacional, os governos do Brasil e dos EUA assinaram acordos diplomáticos, com objetivos militares e econômicos, que resultaram na criação de duas empresas estatais da indústria de base muito importantes para o desenvolvimento de outros setores industriais no país: a Companhia Siderúrgica Nacional e a Companhia Vale do Rio Doce. Elas logo se transformaram em oligopólios em seus respectivos mercados. Em 1953, surge outra companhia mista, a Petrobras, um monopólio de importância estrutural no segmento de energia. Essas três estatais foram criadas nos governos de Vargas, líder desenvolvimentista que promoveu investimentos na indústria pesada, capital intensiva, como é o caso da infraestrutura básica em energia e transporte (Colby, 132). Por sua vez, as obras de engenharia necessárias para erguer esses empreendimentos alavancaram a indústria da construção civil (Chaves, 1985).

Nos anos 1950, destacam-se três medidas importantes para a industrialização. Uma delas foi a Instrução 113 da SUMOC (Superintendência da Moeda e do Crédito), que facilitou a importação de bens de capital para empresas estrangeiras aqui estabelecidas ou interessadas em investir no país. Essa medida permitiu a importação de máquinas e equipamentos sem cobertura cambial, contornando os problemas da carência de divisas estrangeiras e das pressões sobre o balanço de pagamentos (Caputo e Melo, 2009). Ela implicou na atração de investimentos diretos das multinacionais, como foi o caso da indústria automobilística. Houve também a Lei de Tarifas Aduaneiras (Lei n 3.244), de 1957, que "ampliou e consolidou a proteção oferecida à indústria interna em crescimento" (Baer, op. cit., p. 58). Por fim, a Lei de Similares Nacionais 
(Decreto 8.592/1911) foi aplicada de modo mais intenso e abrangente. Ao regulamentar as concessões de isenção de direitos aduaneiros, essa lei impedia benefícios à importação de produto que tivesse um similar já produzido no país (Baer, op. cit.; Caputo e Melo, 2009).

A Lei de Similares estimulou a integração vertical nas empresas e em indústrias como um todo. Os incentivos implicaram em backward e forward linkages, propiciando o estabelecimento de toda a cadeia produtiva, como, por exemplo, na indústria automobilística, que se encadeia a várias outras indústrias, na condição de consumidora. Mas isso também ocorreu na indústria química, na siderurgia e metalurgia, na indústria de papel e papelão, na indústria de alimentos, têxteis etc (Baer, op. cit. pp. 141-142). Sem as medidas protecionistas, não teria sido possível esse crescimento industrial equilibrado, em função da integração vertical, e em ritmo acelerado. Os incentivos também foram planejados e seletivos. "Estimularam-se indústrias dotadas de elevados coeficientes de linkage, e os efeitos de linkage se irradiaram pela economia" (op. cit., p. 150). Em especial, a Instrução 113 da SUMOC jogou papel importante no processo de concentração industrial, pois atraiu investimento direto estrangeiro (IDE) de empresas de grande porte, em um contexto internacional de capitalismo monopolista e de concorrência entre empresas oligopolistas da Europa e dos EUA por posições no mercado mundial. Essa estratégia era uma "forma de contornar a restrição externa" (Caputo e Melo, op. cit., p. 515).

Os anos 1950 também foram importantes na implementação de ações públicas promotoras da industrialização a partir do planejamento estatal. Nesse sentido, destaca-se o Plano de Metas, executado pelo governo Juscelino Kubitschek, que culminou na construção de Brasília. Seus projetos de desenvolvimento concentraramse em cinco setores, todos vinculados a metas: energia, transportes, indústria de base, alimentação e educação. A Instrução 113 da SUMOC foi especialmente importante para o Plano de Metas, por facilitar a atração do capital estrangeiro, sobretudo na indústria automobilística, mas também no alumínio, no cimento e na construção naval (Lessa, 1982; Caputo e Melo, 2009).

No relato da alavancagem estatal à industrialização é imprescindível uma referência ao BNDE (Banco Nacional de Desenvolvimento Econômico), hoje BNDES, devido ao acréscimo da palavra social no nome desse banco público criado em 1952 para propiciar recursos financeiros e técnicos para o esforço desenvolvimentista. Colby (2013) identifica três papeis do BNDES: corrigir falhas de mercado, sobretudo o alto custo do crédito e o volume insuficiente desse recurso fundamental ofertado em prazos longos pelo setor privado; engajar-se em atividades de melhoria e modernização da economia; e por fim, na fase mais recente, a oferta de empréstimos contracíclicos em períodos de crise econômica. ${ }^{23}$ Assim que foi criado na década de 1950, o então BNDE financiou, com impacto, os setores de energia, sobretudo a energia elétrica, e de transporte, vistos como os principais gargalos para o crescimento 
econômico por instituições de planejamento, como a Comissão Mista Brasil-EUA (Baer, op. cit., pp. 62-70; Skidmore, pp. 204-207).

Nos anos 1960, vários autores já avaliavam que a concentração de capital caracterizava a estrutura produtiva brasileira. Cardoso (1968, p. 62) refere-se a ela como inserida em "mercados onde a tendência à monopolização ou ao oligopólio é indiscutível". Esse mesmo autor observa então também que o mercado já era estruturalmente marcado pela "tendência à formação de 'grupos econômicos"', e não mais pela empresa isolada, que havia sido o agente típico na formação inicial do mercado interno.

Analisando a distribuição das empresas industriais em São Paulo, estado com a principal fatia da indústria nacional, Baer (op. cit. p. 99) constata que, em 1960, as firmas com mais de 100 empregados, apesar de serem apenas 4\% do total, eram responsáveis por $63 \%$ da produção industrial paulista. Em 1950, esses números eram respectivamente 3,2\% e 57\%. Após dez anos, a concentração industrial, acentuada desde o início do período referido, era ainda maior, mostrando ser uma tendência do processo produtivo. Esse brazilianista afirma que, naquela década, predominavam as firmas individuais ou pertencentes a famílias. Mesmo havendo grupos gigantescos, constituídos por muitas empresas combinadas, como Matarazzo, Klabin e Renner, a principal tendência eram as empresas fechadas, que se transformavam em sociedades anônimas apenas formalmente, para adquirirem vantagens legais, sendo efetivamente familiares. Mas ele detecta uma propensão crescente à abertura do capital, pelo fato do crédito bancário ser difícil de ser obtido e ter custo elevado (idem, p. 100). Também para Queiroz (1962, p. 160), as empresas abertas são muito poucas.

Bonelli (1980), ao investigar preliminarmente indicadores de concentração industrial no Brasil, apoiado nos dados censitários de 1950, 1960 e 1970, constatou que prevaleceu a tendência ao seu aumento, sendo os índices, respectivamente, $0,768,0,838$ e 0,879. Além disso, ele observa "que o grau de concentração da produção aumentou em todas as indústrias [...], à exceção da Têxtil nos anos 50 (quando se reduziu), da Química e Farmacêutica nos anos 1960 e Alimentos, Bebidas e Fumo nos anos 50 (quando se manteve)" (p. 856). ${ }^{24}$

Maurício Vinhas de Queiroz publicou, em 1962 e 1965, o até então "mais completo estudo disponível sobre os grupos econômicos no Brasil", delimitando os "multibilionários" e os "bilionários" (Cardoso, idem). Ele formula uma hipótese importante para o tema dessas notas de pesquisa:"Como hipótese, poderíamos sugerir que a concentração de capitais - produto do tipo de desenvolvimento em processo no país -, ao invés de levar apenas ao surgimento de gigantescas empresas, assume aqui predominantemente a forma de reuniões de empresas nominalmente diversas, mas integradas por iguais diretores e pela coparticipação acionária" (1962, p. 159). Esse autor explicitou a hipótese de que o tipo de desenvolvimento então existente no país não só produzia a concentração de capital como o índice de concentração era elevado. Considera isso surpreendente "diante do nível relativamente atrasado de nosso 
desenvolvimento econômico" (p. 160). Mas a mencionada teoria do desenvolvimento desigual e combinado pode também aqui ser evocada para auxiliar na compreensão dessa disparidade, para a qual contribui muito a presença do capital estrangeiro, inclusive em setores industriais que mobilizam cadeias produtivas.

Queiroz (1965, p. 46) procurou identificar e analisar os grupos bilionários, "aqueles cujo capital próprio das empresas interligadas somasse um bilhão ou mais de cruzeiros", em valores de 1962. Incluiu nesse grupo um universo de 276 empresas, no qual 55 delas formariam um subgrupo, os multibilionários, "cujo capital próprio [...] ultrapassa a cifra dos quatro bilhões de cruzeiros". Detectou duas peculiaridades: "o grau de concentração relativamente alto e a predominância de empresas fechadas e rigidamente controladas". Tais características foram consideradas semelhantes às de outros países que estavam então em etapa equivalente de desenvolvimento (Queiroz, 1962, p. 161). Além disso, ele distinguiu os seguintes modos de concentração de capital no Brasil: horizontal, vertical e desconectada. Na horizontal, as empresas do grupo lidam, basicamente, com os mesmos produtos ou serviços, caso do grupo Cofermat, de capital francês, que fabrica materiais para a construção civil. A concentração vertical, então raramente completa, abrange "desde a produção de toda a matéria prima à entrega do produto acabado ao consumidor", caso do grupo nacional Biagi. Por fim, a concentração desconectada, a mais observada na ocasião, ocorre quando as empresas do grupo atuam em áreas diferentes, como o grupo Scarpa, "que reúne uma fábrica de bebidas (cerveja Caracu), uma fábrica têxtil e empresas de comércio de automóveis". Em intensidades distintas, os três modos de concentração podem abarcar grupos que possuem setores de atividade principal e secundária, e até mesmo terciária ou quaternária (Queiroz, 1965, p. 57). Enquanto os modos de concentração horizontal e vertical levam ou podem levar ao monopólio do mercado, isso é pouco provável na concentração desconectada. A hipótese para explicar a frequência alta desse último modo de concentração é que "isto se relaciona talvez com o relativo atraso industrial do Brasil". A pesquisa liderada por Queiroz observa também outros dois aspectos: os grupos mistos, de capital estrangeiro e nacional, questão que remete, ao modelo de desenvolvimento associado-dependente e ao debate sobre os interesses comuns e distintos desses dois capitais; e a diversificação de setores de atuação nos grupos econômicos, que podem combinar empresas industriais, financeiras e agrárias.

O setor principal de atuação dos 55 grupos multibilionários distribuía-se da seguinte forma: 78,1\% era industrial, 12,8\%, comercial e 9,1\%, financeiro. Queiroz (1965) constata que, dos 55 grupos multibilionários, 29 eram estrangeiros, 24, nacionais e dois, mistos. Quanto à data de fundação, a maioria dos nacionais era anterior a 1914. Em relação aos estrangeiros:"a maior parte se instalou depois de 1919. Período particularmente auspicioso para o estabelecimento de grupos estrangeiros parece que foi o decênio 1919-1929, quando se verificou um verdadeiro rush do café. Igualmente, após 1945, as condições foram propícias à instalação de grandes grupos estrangeiros. Sete grupos multibilionários estrangeiros aqui se fixaram depois dessa 
data" (p. 52). À medida que algumas políticas de desenvolvimento atraíram a grande empresa estrangeira, atraíram capital concentrado desde a origem.

Os limites do trabalho impedem, aqui, uma maior exploração dos dados de Queiroz (1962, 1965), mas, se os confrontarmos, por exemplo, com o peso dado no Plano de Metas (1956-1961) às indústrias de base (setores siderúrgico, de alumínio, cimento, celulose, automobilístico, mecânica pesada e químico) algumas hipóteses se sustentam. ${ }^{25}$ Dos 55 grupos multibilionários, 67,1\% atuavam na indústria de base. Ao abordarem a política cambial da Instrução 113 da Sumoc e o documento oficial do Plano de Metas, Caputo e Melo (2009, p. 519) afirmam que"quatro metas [...] receberiam equipamentos através da referida política cambial: alumínio, cimento, indústria automobilística e construção naval. A Instrução 113 teria então uma participação no alcance das metas, já que era o dispositivo legal que permitia a entrada das máquinas e equipamentos sem cobertura cambial, na forma de investimento direto estrangeiro". Ademais, foi visto que, a partir de 1930, a restrição de divisas estrangeiras forçou o Estado a adotar medidas prejudiciais às importações, que induziram à industrialização por substituição de importações e beneficiaram as indústrias já existentes, de bens de consumo não duráveis e duráveis e de bens de capital a elas correspondentes, que tinham também passado por um primeiro surto industrializante durante a Primeira Guerra Mundial, apoiado no mercado interno. No pós-1930, a demanda interna por bens produzidos no país passa a ser uma variável fundamental para o desenvolvimento industrial e também para a produção agrícola, que, antes, era desproporcionalmente dirigida à exportação.

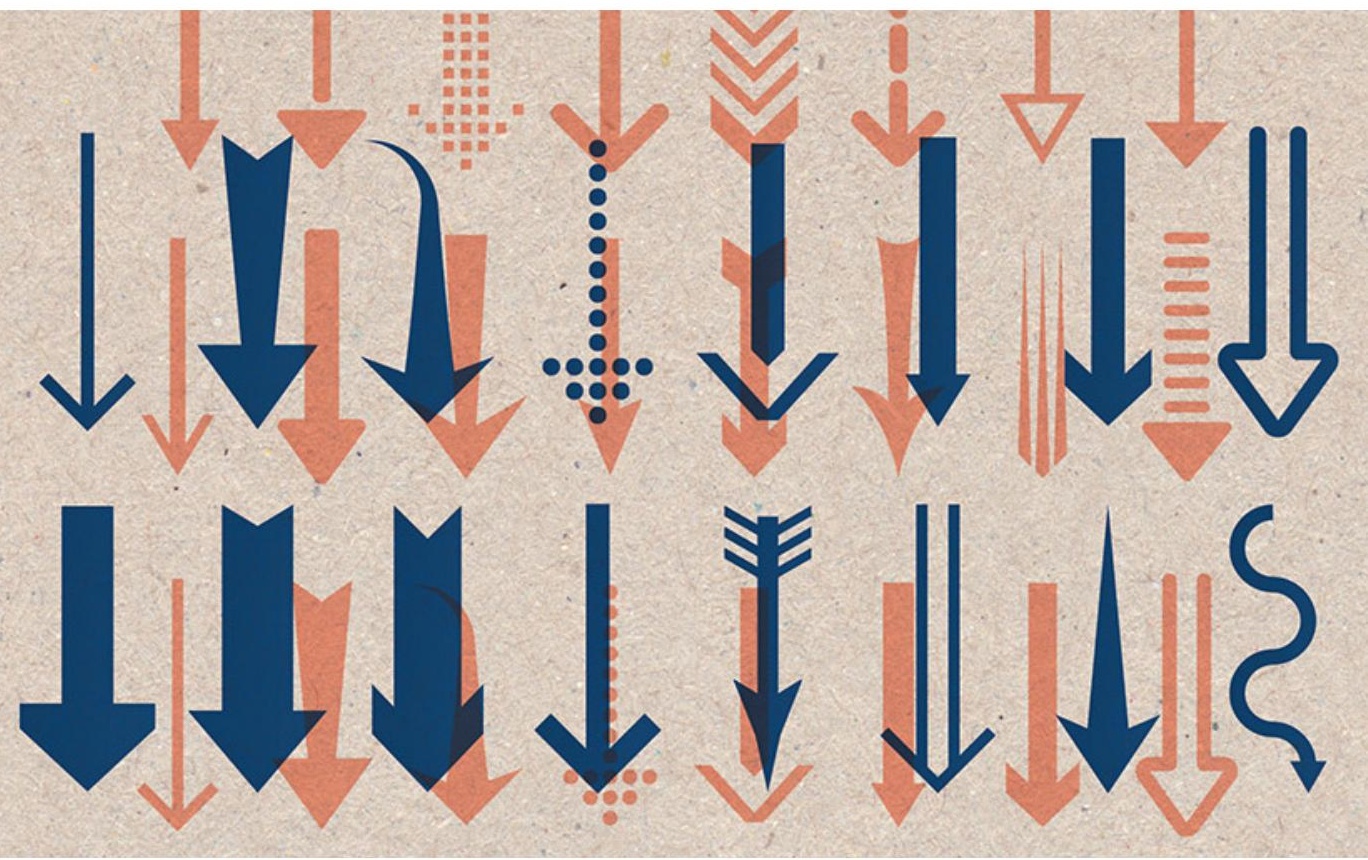


Outro capítulo importante da relação entre Estado e acumulação de capital no período nacional-desenvolvimentista se desenvolveu durante o regime militar, especialmente nos governos Médici e Geisel. No entanto, esse período extrapola as breves notas de pesquisa aqui apresentadas.

\section{CONSIDERAÇÕES FINAIS}

Tanto nos países desenvolvidos como nos países em desenvolvimento, a acumulação de capital, nas diversas fases do capitalismo, ocorre por mecanismos de mercado e pela política. No processo de acumulação, o capital, interagindo com o Estado, concentra-se e, em seguida, centraliza-se. As modalidades específicas de relação entre o Estado e o capitalismo variam de acordo com especificidades econômicas e políticas nacionais e internacionais. Um aspecto importante a ser observado são as crises do capitalismo e as respostas para enfrentá-las.

Quando se trata da acumulação de capital exclusivamente no mercado nacional, sem que sua realização dependa de ações políticas externas, o Estado a auxilia com políticas públicas internas, como a construção de obras de infraestrutura, compras do setor privado, regulação de diversos preços etc. E o Estado também alavanca a acumulação de capital pelas políticas públicas externas, pela diplomacia e pela guerra, como se pode observar desde o velho colonialismo do mercantilismo, que propiciou o desenvolvimento do Império Britânico e do Império Holandês, até o imperialismo militar e econômico do século XX, cuja maior expressão está nos EUA. Tais papéis do Estado são especialmente importantes para apoiar as exportações de bens e serviços e a internacionalização da produção, mas também para propiciar fontes externas de matéria prima, mão de obra barata, oportunidade de negócios e assim por diante.

As modalidades da relação entre o Estado e a acumulação de capital mudam historicamente e, a partir da crise de 1929, diante dos riscos econômicos, políticos e militares associados aos interesses e ao desempenho do sistema produtivo capitaneado pelo capital monopolista, tornam-se mais complexas em termos técnicos e políticos, impactando nas decisões internas e externas de política econômica e nas relações internacionais.

A competição econômica relevante passa a se dar, sobretudo, entre gigantes do mercado, associados aos seus Estados, que procuram lhes propiciar, por meios políticos e, se necessário, militares, condições de acumulação e respostas às crises cíclicas do sistema econômico. Os papéis econômico e militar do Estado podem ser apreendidos pela idéia de dependência estrutural do Estado em relação ao capital.

No Brasil, tal dependência induziu o Leviatã, em um primeiro momento, a garantir a concentração do capital no setor cafeeiro. Mas, em função dos problemas objetivos que se apresentaram a partir da crise de 1929, o poder público, desde Vargas, passou a alavancar a mudança de uma estrutura produtiva exclusivamente agrícola para uma economia urbano-industrial. Nesse sentido, foram implementadas, entre 
outras medidas relevantes, políticas cambiais restritivas às importações e políticas protecionistas; além disso, o Estado engajou-se, por meio de companhias mistas, em empreendimentos industriais capital-intensivos, nos setores de mineração, siderurgia, petróleo e energia elétrica, cujas empresas já surgiram como oligopólios. Munindose do planejamento econômico e de um banco público de desenvolvimento criado para financiar projetos de grande porte em um contexto nacional de relativa escassez de capital e de ausência de oferta de crédito de longo prazo pelos bancos privados, o Estado deu suporte a projetos, em aliança com agentes econômicos internos e externos, que viabilizaram cadeias produtivas nas indústrias de transporte, química, siderurgia, energia elétrica, entre outras. A atração de corporações estrangeiras possibilitou a implantação de indústrias novas, como a automotiva, ao mesmo tempo em que produziu efeitos de encadeamento industrial. A proteção ao mercado interno, inserida na estratégia de industrialização por substituição das importações, propiciou a concentração e a centralização do capital tanto em indústrias de bens de consumo não duráveis, como em indústrias de bens duráveis. Uma questão pertinente às estratégias políticas de acumulação de capital diz respeito às relações entre capital nacional e capital estrangeiro e ao caráter dependente ou autônomo do desenvolvimento.

Já nos anos 1960, a concentração de capital era uma característica da estrutura produtiva, particularmente no estado de São Paulo, embora não só. Os indicadores de concentração industrial evoluíram positivamente, década a década, desde os anos 1950, ainda que, em um primeiro momento, predominaram as empresas individuais ou familiares, e não o capital aberto. A investigação, em perspectiva histórica de médio e longo prazo, da relação entre o processo de concentração do capital industrial e as políticas do Estado é um contraponto teórico-empírico à ideologia dos modelos econômicos abstratos, que preconizam explicações para o crescimento e o desenvolvimento lastreadas na vigência de um reino decisório exclusivamente centrado nos agentes operando em condições de laissez-faire.

\footnotetext{
Notas

'Esse artigo é parte de um trabalho apresentado no $38^{\circ}$ Encontro Anual da Anpocs, em 2014.

${ }^{2}$ Idem, p. 729.

${ }^{3}$ Idem, p. 876

${ }^{4}$ Idem, ibidem.

${ }^{5}$ Idem, p. 730

${ }^{6}$ Idem, p. 729

${ }^{7}$ Baran \& Sweezy (1966, pp. 18-19).

${ }^{8}$ Nos EUA, essa lacuna é preenchida pelo marxista Hary Braverman (1974), na obra Labor and Monopoly Capital. Mandel (1972) também destaca o papel da revolução tecnológica na conformação da fase na qual o capitalismo ingressa no pós-1945.

${ }^{9}$ Baran \& Sweezy (op. cit., p. 19).

${ }^{10}$ Idem, pp. 120-121.

${ }^{11}$ Mandel (1972[1975], p. 310).
} 


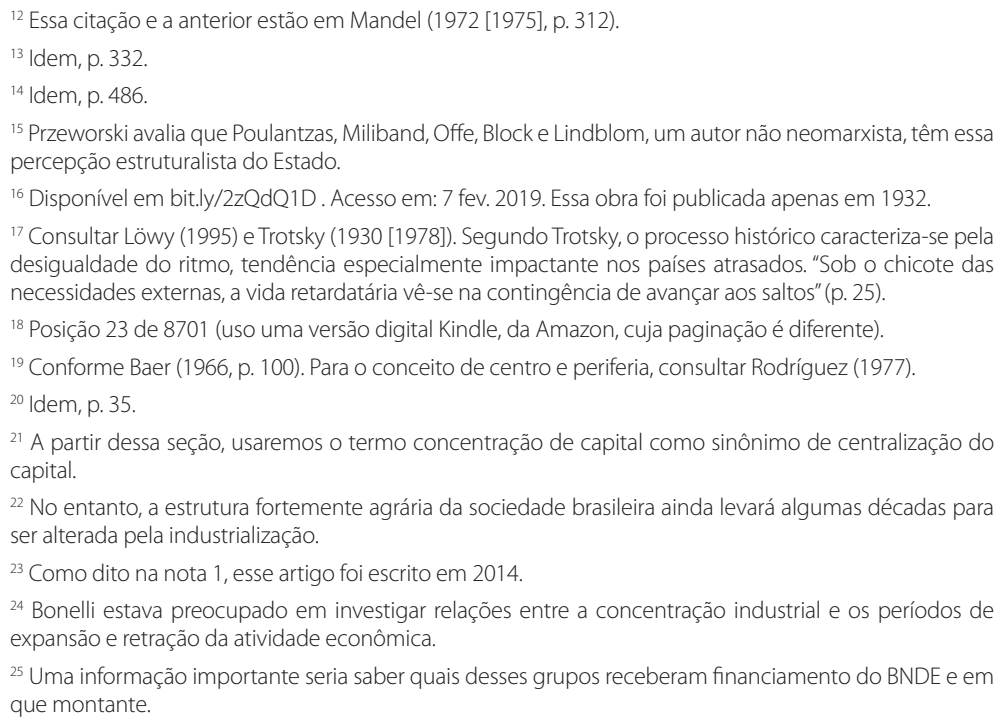

\section{Referências}

ALEM, A. C. e CAVALCANTI, C. E. "O BNDES e o Apoio à Internacionalização das Empresas Brasileiras: Algumas Reflexões". Revista do BNDES, Rio de Janeiro, v. 12, n. 24, p. 43-76, 2005.

BAER, W. A industrialização e o desenvolvimento econômico no Brasil. Rio: Fundação Getúlio Vargas, 1965 [1966].

BARAN, P. A. \& SWEEZY, P. Monopoly capital. Middlesex, Penguin Books, 1966[1970].

CAPUTO, A. C. e MELO, H. P. "A industrialização brasileira nos anos de 1950: uma análise da instrução 113 da SUMOC". Estudos Econômicos (São Paulo), v. 39, n 3, 2009.

CARDOSO, F. H. "Hegemonia burguesa e independência econômica: raízes estruturais da crise política brasileira". In Furtado, C. et alli, Brasil: tempos modernos. Rio, Paz e Terra, 1968.

CARDOSO, F. H. A construção da democracia: estudos sobre a política brasileira. São Paulo: Siciliano, 1993.

CHAVES, M. A Indústria de Construção no Brasil: desenvolvimento, estrutura e dinâmica. Dissertação de mestrado em Economia Industrial. Rio de Janeiro: UFRJ, 1985.

COLBY, S. E. Searching for institutional solutions to industrial policy challenges: a case study of the Brazilian development bank. Johns Hopkins University, mimeog., 2013.

EVANS, P. A tríplice aliança: as multinacionais, as estatais e o capital nacional no desenvolvimento dependente brasileiro. Rio de Janeiro: Zahar, 1980.

EVANS, P. Autonomia e parceria: Estados e transformação industrial. Rio de Janeiro: Ed. UFRJ, 1995 [2004].

FURTADO, C. Formação econômica do Brasil. Rio de Janeiro: Fundo de Cultura, 1959[1964]. 
JOHNSON, C. A. MITI and the Japanese Miracle. Stanford: Stanford University Press, 1982.

LESSA, C. Quinze anos de política econômica. São Paulo: Brasiliense, 1982.

MANDEL, E. An Introduction to Marxist Economic Theory. Australia: Resistance Books, 1967 [2002].

MANDEL, E. Late capitalism. London: Lowe \& Brydone Printers, 1972 [1975].

MARX, K. O capital: crítica da economia política, Livro I, vl. 2. Rio de Janeiro: Civilização Brasileira, 1867 [1998].

MELLO, J. M. C. de. O capitalismo tardio. São Paulo: Brasiliense, 1982.

OFFE, C. Problemas estruturais do Estado capitalista. Rio de Janeiro: Tempo Brasileiro, 1984.

PRZEWORSKI, A. Estado e economia no capitalismo. Rio de Janeiro, Relume Dumará, 1990 [1995].

RODRÍGUEZ, O. On the conception of the centre-periphery system. Santiago, Chile: Cepal Review, 1977.

QUEIROZ, Maurício Vinhas de "Os grupos bilionários". Revista do Instituto de Ciências Sociais, 2-1, pp. 47-77, 1965.

SUZIGAN, W. Notas sobre desenvolvimento industrial e política econômica no Brasil na década de 1930. São Paulo: Revista de Economia Política, vol.4, n.1, jan-mar/1984.

TROTSKY, L. História da revolução russa. A queda do tzarismo. Rio de Janeiro: Paz e Terra, vl. 1, 1930 [1978].

VAN DER LAAN, C. R.; CUNHA, A. M.; FONSECA, P. C. D. Os Pilares Institucionais da Política Cambial e Industrialização nos Anos 1930. São Paulo: Revista de Economia Política (Impresso), v.32, p.597-614, 2012. 